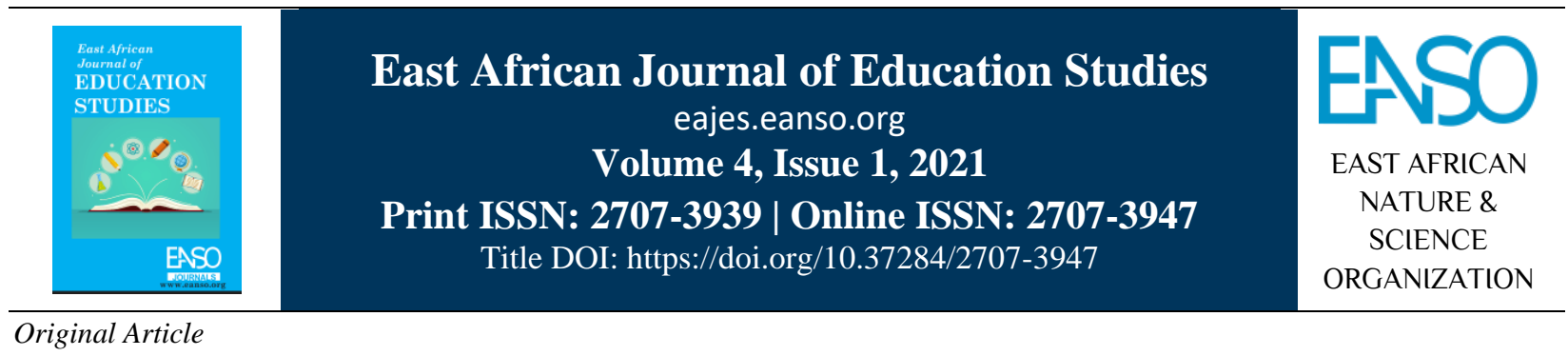

\title{
Availability of Teaching and Learning Materials on Creative Play Activities among Public Pre-Primary School Children in Bureti Sub-County, Kenya.
}

\author{
Evelyn Chepngeno Mitei ${ }^{* 1} \&$ Dr. Teresa Mwoma, PhD ${ }^{1}$ \\ ${ }^{1}$ Kenyatta University, P. O. Box 43844-00100, Nairobi, Kenya. \\ *Correspondence Email: evelynmitei@gmail.com.
}

Article DOI: https://doi.org/10.37284/eajes.4.1.476

\section{Date Published: ABSTRACT}

16 November 2021 Creative activities play a critical role in improving intellectual, emotional, and social skills among children. This study aimed to explore the availability of

Keywords: teaching and learning materials on creative play activities among public preprimary school children in Bureti Sub-County, Kenya. The research adopted a
descriptive survey design and was guided by Sarah Smilansky's theory which Activities, emphasises the child-centred approach in teaching creativity. Sarah Smilansky's

Teaching,

Learning Materials,

Preschool Children,

Teacher's Attitude,

Time. theory lays emphasis on allowing young children to control their way of learning by stressing self-expression. The population targeted was 135 public pre-primary schools in Bureti Sub-County. Ten per cent (10\%) of the target population representing 14 public pre-primary schools was utilised during the pilot study. The sample size for the study was 236 participants. This comprised 92 head teachers and 144 preschool teachers from 121 pre-primary schools in Bureti SubCounty. Questionnaires and observation schedules were utilised to gather data. The statistical package for social sciences (SPSS) version 23 was utilised to organise data for analysis. Quantitative data were analysed using descriptive statistics. The data was presented in the form of percentage tables. The results revealed that $(73.9 \%)$ of the respondents indicated that there was insufficient learning and teaching materials listing out that the most available materials are manila papers, clay, paints, tires, pencils, and maise corps. The study recommended that learning and teaching resources should be made available by the County Government for learners to use while embracing creative play activities. There is also a need for adequate time to be allocated to play to enhance creative play activities in school. 
APA CITATION

Mitei, E. C., \& Mwoma, T. (2021). Availability of Teaching and Learning Materials on Creative Play Activities among Public Pre-Primary School Children in Bureti Sub-County, Kenya. East African Journal of Education Studies, 3(1), 82-88. https://doi.org/10.37284/eajes.4.1.476.

\section{CHICAGO CITATION}

Mitei, Evelyn Chepngeno, \& Teresa Mwoma. 2021. “Availability of Teaching and Learning Materials on Creative Play Activities among Public Pre-Primary School Children in Bureti Sub-County, Kenya”. East African Journal of Education Studies 3 (1), 82-88. https://doi.org/10.37284/eajes.4.1. 476.

\section{HARVARD CITATION}

Mitei, E. C. and Mwoma, T. (2021) "Availability of Teaching and Learning Materials on Creative Play Activities among Public Pre-Primary School Children in Bureti Sub-County, Kenya”, East African Journal of Education Studies, 3(1), pp. 82-88. doi: 10.37284/eajes.4.1. 476.

\section{IEEE CITATION}

E. V. Mitei, \& T. Mwoma, "Availability of Teaching and Learning Materials on Creative Play Activities among Public PrePrimary School Children in Bureti Sub-County, Kenya", EAJES, vol. 3, no. 1, pp. 82-88, Nov. 2021.

\section{MLA CITATION}

Mitei, Evelyn Chepngeno, \& Teresa Mwoma. “Availability of Teaching and Learning Materials on Creative Play Activities among Public Pre-Primary School Children in Bureti Sub-County, Kenya". East African Journal of Education Studies, Vol. 3, no. 1, Nov. 2021, pp. 82-88, doi:10.37284/eajes.4.1.476.

\section{INTRODUCTION}

Creative play activities are very important in the optimal development of a child. Play is an important activity in early childhood education because it can promote the holistic development of preschool children. Creative play activities comprise activities like drawing, painting, singing, modelling, puppets constructing blocks and wires and dramatisation. According to Banaji (2011), children acquire essential knowledge and skills through plays. Children play to practice skills and in the process encounter new challenges leading to deeper learning. He agrees that children are highly creative, have a tendency to fantasise, experiment, and explore their physical and conceptual environment.

A study by Brittany (2017) established those creative activities help children to know more about sorting, grouping, balancing shapes and colours. These are concepts that they will encounter as they proceed on to the next grade in learning. Engaging children in creative activities offers preschool children an avenue to express themselves. They express their feelings in creative activities like painting and playing with dough (Brittany, 2017). Creative play activities enhance focus and attention making learning lively and enjoyable compared to the conventional methods, which can be boring.
The research conducted by Kim (2011) revealed that creativity among kindergarten children has been decreasing since 1990 . The value of creative play activities is very low in Nigeria and South Africa. There is the problem of inadequate funding to preschools, incompetent educators who are not informed about play as pedagogy, and lack of facilities (Florence, 2016). In Kenya, the situation is no better; despite the fact that the play is recognised, many preschool children are not given adequate time for free play. There is also the problem of reduced time for creative play activities to focus on mathematics and reading.

Creative play activities are very significant to young children as it helps them to develop emotionally, socially, physically, and intellectually. Biukwayo (2013) notes that both real and imaginary experiences are required to inspire young children on how to learn. Despite the fact that creative play activities are very important, many children are not accessing proper play activities. In Kenya, more and more women are joining the workforce. This has led to the establishment of early childhood centres in church buildings, previously residential homes, or sometimes makeshift structures, or in the shade of trees (Nga In some places, there is hardly enough space for creative play activities. Learning has been ineffective in most preschools with children showing difficulties in mastering reading, manipulative and interpersonal skills (Manduku et 
al., 2017). The study, therefore, sought to explore whether the availability of teaching and learning materials influences creative play activities among public pre-primary school children in Bureti SubCounty, Kenya.

\section{LITERATURE REVIEW}

\section{Theoretical Underpinning}

This research is based on the theory advanced by Sarah Smilansky (2006). The theory outlines four stages of the games, which include functional games, constructive games, pretend games, and rule games. In functional play, children interact with materials they see, smell, touch, and manipulate to learn more. The more and more they play with materials like building blocks or sand, they explore their weight and size and may use them to make a purposeful construction like a house or a bridge.

Children learn best during play. When teachers use play as a teaching method, all aspects of children's growth and development are strengthened. This is as a result of play positively enhancing emotional, social, cognitive, physical, language and reading capabilities. Play is very significant in the healthy development of children and self-regulation improvement (Ginsburg \& Molten, 2012). In dramatic play, a child pretends alone. The child recalls the past experience, uses relevant gestures and words. When a child pretends, she or he creates a mental picture to represent real objects or events. To solve a problem in Mathematics, for instance, a child has to create a mental picture so as to know whether to add, subtract, multiply or divide. Pretend play encourages a child's imagination at the preschool level. This is crucial in a child`s learning in the future since it highlights how children should be helped in the development of talents by using creative play activities.

\section{Empirical Studies and Knowledge Gaps}

For effective and efficient implementation of creative activities in preschools, it is essential that the child's learning environment be enriched with lots of open-ended materials. Willis and HymonParker (2010) established those successful, resourceful activities enhance educational plans as an executives' school team plan with parents to uphold profits of entirely crucial materials. Likewise, the preschool instructor ought to attempt to ad-lib and make different materials utilising modest locally accessible materials. As per Whitebread (2010), educators cannot utilise preresearchers in play activities since they do not have play amenities, recreation amenities, physical infrastructures, and play resources. Further, they note that good planning of materials, equipment, and encounters ought to consider an assortment of a variety of materials for development for the improvement of psychomotor abilities. Further, common highlights including rope structures, even tree trunks, and brief plans for actual difficulties, expand the opportunities for play activities.

The physical environment should be enriched with a range of materials that encourage creative play like sand, water, ropes, crayons, wheels, construction blocks, and even outdoor play apparatus like swings and hooks. Onyango (2014) suggests that teachers should set learning corners full of resources. This will encourage the children to explore and experiment more. The research conducted by Mutindi et al. (2016) shows that the facilities and materials used in some preschools are inadequate and teachers do not make maximum use of them.

The literature reviewed indicates that creative play activities in preschool are greatly influenced by the amount of time allocated to it, teachers' attitude, availability of teacher learning materials. Other factors include lack of relevant skills and lack of interest and motivation of the teacher. From the findings, most researches focus on developing countries like Kenya. The findings from the western countries cannot be generalised to the Kenyan situation because of the big difference that lies between them in terms of socio-cultural factors.

\section{METHODOLOGY}

\section{Research Design and Target Population}

A descriptive survey design was used. This survey design was suitable for research since it captured the opinions, beliefs, and attitudes of teachers of preschool and headteachers of the schools with preschools on the creativity of children. Survey research was used in studies that have an individual 
as units of analysis. It involves some individuals who must serve as respondents of informers (Rao, 2002). Descriptive survey designs were used since it tends to be utilised when gathering data about individual' convictions (Orodho and Kombo, 2002). The study targeted preschool pupils' preschool teachers and headteachers from 135 pre-primary schools in the Bureti sub-county. However, 10\% representing 14 public pre-primary schools from the total were used during piloting. These schools were chosen based on a random sampling technique. The headteachers and preschool teachers were targeted since they interact with preschool children on a daily basis except during the weekends and holidays, so they possess important information regarding the creative play activities of children. The study targeted 121 head teachers and 242 preschool teachers.

\section{Sampling Techniques and Sample Size}

Simple random sampling was utilised to sample 92 headteachers since they are in charge of all functions in the school and 144 preschool teachers were sampled purposively since they are the ones having control of teaching in preschools.

The researcher used a questionnaire as a research instrument for 92 head teachers and 144 preschool teachers and an interview guide for preschool children.

\section{Pilot Study}

The pilot study was conducted in two schools chosen randomly. The schools were not included in the final study. The questionnaires to be administered in the pilot study were analysed and stored for future reference. Piloting involved 2 headteachers, 2 preschool teachers, and 3 preschool children. The respondents were given the questionnaires and were given instructions on how to fill them. Piloting was done to check the validity and reliability of research instruments. The tools were assessed for content validity, that is the range to which the form insides such as the use of correct language, verdict structures, and whether requests are to the equal of the envisioned respondent. The researcher used certified tools to discourse the aims of the study. Reliability was established using the test-retest method applying Kuder-Richardson (KR20) formula. A correlation coefficient of 0.95 was established, which was more than recommended 0.7 .

\section{Data Collection Procedures, Analysis, and Presentation}

Before data collection, the researcher asked for permission from the Bureti Sub-County office, Kericho County. During the data gathering process, the researcher visited the schools and made arrangements for gathering data. Questionnaires were self-administered to the respondents and later interview sessions for social workers were arranged on the agreed date convenient to her. Quantitative data was collected and recorded through questionnaires; then the edited, coded, and tabulated data were analysed using the 23rd edition of the Statistical Software Package for Social Sciences (SPSS). The percentages and statistical frequencies described are used for closed-ended questions.

\section{RESULTS AND DISCUSSIONS}

\section{General and Demographic Information}

Table 1: Availability of Learning and Teaching Materials that Enhance Children's Creative Play Activities

\begin{tabular}{lllc}
\hline \multirow{2}{*}{ Learning \& Teaching materials } & \multicolumn{2}{c}{ Availability of these materials in school } \\
\cline { 3 - 4 } & YES & NO \\
\hline A & Plasticine & $90(62.5 \%)$ & $54(37.5 \%)$ \\
B & Clay & $93(64.6 \%)$ & $51(35.4 \%)$ \\
C & Crayons & $36(25.0 \%)$ & $108(75.0 \%)$ \\
D & Paints & $129(89.6 \%)$ & $15(11.4 \%)$ \\
E & Scissors & $72(50 \%)$ & $72(50 \%)$ \\
\hline
\end{tabular}




\begin{tabular}{lllc}
\hline & Learning \& Teaching materials & Availability of these materials in school \\
F & Manila papers & $117(88.6 \%)$ & $15(11.4 \%)$ \\
G & Tyres & $72(52.2 \%)$ & $66(47.8 \%)$ \\
H & $\begin{array}{l}\text { Pencils } \\
\text { I }\end{array}$ Maize cobs & $128(94.1 \%)$ & $8(5.9 \%)$ \\
$\mathrm{J}$ & $\begin{array}{l}\text { There are adequate resources in class for learners to } \\
\text { interact with. }\end{array}$ & $38(26.4 \%)$ & $81(56.3 \%)$ \\
K & $\begin{array}{l}\text { The physical environment in school encourages } \\
\text { children to be creative. }\end{array}$ & $71(49.3 \%)$ & $73(50.7 \%)$ \\
L I am not aware of how to teach creatively. & $8(5.8 \%)$ & $130(94.2 \%)$ \\
\hline
\end{tabular}

From Table 1, an average of $78.5 \%$ of the respondents indicated that there is the availability of the above materials. Crayons were unavailable; however, the learners used locally available materials like charcoal, petals of different colours. This is an eye-opener to the education stakeholders and government to guarantee the availability of the latter so that pupils will have many choices on the verge of embracing the creative play activities. Furthermore, scissors were seen to be available in half of the schools and not available in other schools. Asked whether the listed resources are adequate for learners to interact with, the majority of $106(73.6 \%)$ respondents indicated no, while 38 (26.4\%) respondents agreed by indicating yes. This implies that some materials such as crayons are not available in schools which hinder the realisation of various talents.

Regarding whether the physical environment in school encourages children to be creative, the majority of $73(50.7 \%)$ respondents disagreed by indicating a "no" answer while 71 (49.3\%) respondents agreed by indicating "yes". This indicates that even though numerous participants indicated "no", a good number of the participants indicated "yes", indicating that the physical environment is a factor that influences children's creativity. This corroborates with the study done by Ewing and Tuthill (2012) who said that the physical environment helps to build a child's creativity.
Concerning whether they are now aware of how to teach creatively, the majority of $130 \quad(94.2 \%)$ respondents disagreed by indicating a "no" while 8 $(5.8 \%)$ respondents agreed by indicating "yes". This shows that some quarters of teachers do not know how to teach creatively. This concurs with the results of the research by Tonui (2015), who said that monitoring and evaluation of teachers should be done to enhance perfection.

On the other hand, headteachers were inquired to specify whether they have sufficient learning and teaching materials that promote creativity among the school children. The majority of $65(73.9 \%)$ disagreed by indicating a "no" answer, while 23 (26.1\%) respondents agreed. The majority of the headteachers indicated manila papers, clay, paints, tyres, pencils, and maise cobs as resources that enhance creativity amongst children in school. This is indicated in the findings of the study done by Brinkman (2010). Furthermore, the majority of 58 $(66.7 \%)$ respondents rated their pre-primary children in their schools as moderately creative, 19 $(21.8 \%)$ respondents rated them as very creative, while $10(11.5 \%)$ respondents rated them as low level.

To expound how the availability of learning and teaching materials influence children's play creative activities, preschool teachers were inquired to specify their perception of the following statements in Table 2. 
Table 2: Pre-school Teachers' Perception on Impact of Availability of Teaching and Learning Materials on Children's Creative Play Activities

\begin{tabular}{llllllll}
\hline Statements & SD & D & UN & A & SA & Mean & Std. Dev. \\
\hline I share learning intentions with the & - & 8 & 13 & 65 & 52 & 4.17 & 0.825 \\
learners. & & $(5.6 \%)$ & $(9.0 \%)$ & $(45.1 \%)$ & $(36.1 \%)$ & & \\
\hline $\begin{array}{l}\text { I encourage children in my class to } \\
\text { improvise and experiment. }\end{array}$ & & $(5.6 \%)$ & $(9.0 \%)$ & $(53.5 \%)$ & $(22.2 \%)$ & & \\
\hline I always adapt to children's ideas. & - & 8 & 7 & 57 & 66 & 4.30 & 0.772 \\
& & $(5.6 \%)$ & $(4.9 \%)$ & $(39.6 \%)$ & $(45.8 \%)$ & & \\
\hline I ask children open-ended questions & - & 8 & 7 & 63 & 66 & 3.84 & 0.816 \\
& & $(5.6 \%)$ & $(4.9 \%)$ & $(43.8 \%)$ & $(45.8 \%)$ & & \\
\hline
\end{tabular}

Pre-schoolteachers were inquired to specify the extent to which they share learning intentions with the learners. $8(5.6 \%)$ participants disagreed, 13 $(9.0 \%)$ participants were undecided, majority of 65 (45.1\%) participants agreed, while $52(36.1 \%)$ participants agreed strongly, having a mean of 4.17 and standard deviation of 0.825 . Therefore, numerous participants were in agreement. This implies that preschool learners in Bureti SubCounty share learner intentions corresponding to the results of the research carried out by Cremin (2010), who expressed that teachers act as the parents of children at school and therefore share a lot with them help them during their development.

Regarding whether they encourage learners to perform experiments, $8(5.6 \%)$ respondents disagreed, 13 (9.0\%) participants were undecided, majority of $77(53.5 \%)$ participants agreed, while 32 $(22.2 \%)$ participants agreed strongly, having a mean of 4.02 and standard deviation of 0.772 . Therefore, numerous participants were in agreement hence corroborating with the results of the research conducted by Copple (2009), who quoted that experimental programs are very vital to a child's development.

Concerning whether preschool teachers always adapt to children, 8 (5.6\%) participants disagreed, 7 (4.9\%) participants were undecided, majority of 57 (39.6\%) participants agreed, while $66(45.8 \%)$ participants agreed strongly. They have a mean of 4.30 and a standard deviation of 0.803 . This means that numerous participants were in agreement hence corroborating with the results of the research conducted by Baker (2010), who argued that teachers should be the first in adapting to children.
This will ease children's adaptation to the new environment that enhances creative play activities.

On whether they ask children open-ended questions, 8 (5.6\%) participants disagreed, 7 (4.9\%) participants were undecided, 63 (43.8\%) participants agreed, while the majority of 66 $(45.8 \%)$ participants agreed strongly. They have a mean of 3.84 and a standard deviation of 0.816 . Therefore, numerous participants agreed strongly indicating that open-ended questions help to diversify children's thoughts.

Furthermore, preschool teachers were asked to indicate how often they do attend seminars and workshops that help them boost the creativity of pupils. $37(25.7 \%)$ respondents indicated that they attend once in a term, majority of $79(54.9 \%)$ respondents indicated that they attend twice a year, while $28(19.4 \%)$ respondents indicated that they have never attended. This gives a clear indication that seminars organisation should be embraced and increased by the government. On the other hand, they were inquired the specify the amount of time they allow learners to engage in a free choice of activities. $57(39.7 \%)$ respondents indicated that they offer 10 to 20 minutes, majority of $64(44.4 \%)$ respondents indicated that they give 20 to 35 minutes, while $23(16.0 \%)$ respondents indicated that they offer between 35 to 60 minutes. Based on the findings of the study done by Brittany (2017), children in schools should be given not less than 30 minutes to engage in activities of their choice. This has been depicted in this study since the majority indicated that they give the children a time between 20 to 35 minutes. 


\section{CONCLUSIONS}

Based on the findings, teaching and learning should be made available for swift dispensation of creative play activities. The physical environment of the school serves as an encouragement for learners to be creative and therefore the school ought to make the physical appearance as good as possible. Therefore, teachers should be aware of how to teach creatively and embrace the same in all lessons.

The study recommends that learning and teaching resources should be made available by the government for learners to use while embracing creative play activities.

\section{REFERENCES}

Banaji, S. (2011). Creativity: a rhetorical approach. Sefton-Green et al (eds).

Biukwayo, H. N. (2013). Pre-school teachers' use of scaffolding method in teaching mathematics: $A$ case study of Mbeya Province, Tanzania. (Unpublished M.Ed. Thesis) Dar-es-salaam University.

Brinkman, D. J., (2010). Teaching creative Arts. Education Policy Review, III, 48-50.

Brittany, W. (2017). Technology teaching resources. https://www.brittanywashburn.com/ 2017/05/

Copple, C., \& Bredekamp, S. (2009). Developmentally appropriate practice in early childhood programs serving children from birth through age 8. National Association for the Education of Young Children. 1313 L Street NW Suite 500, Washington, DC 22205-4101.

Cremin, T., \& Baker, S. (2010). Exploring teacherwriter identities in the classroom: Conceptualising the struggle. English Teaching: Practice and Critique, 9(3), 8-25.

Ewing, V., \& Tuthill, L. (2012). How Creative Is Your Early Childhood Classroom? Exchange: The Early Childhood Leaders' Magazine Since 1978, 207, 86-90.

Florence, M. Itegi (2016). Financing Secondary Education in Kenya: Exploring Strategic
Management Approach for Improving Quality of Education. Universal Journal of Educational Research, 4(5), 949-955.

Kim, K. H. (2011). The creativity crisis: The decrease in creative thinking scores on the Torrance Tests of Creative Thinking. Creativity research journal, 23(4), 285-295.

Manduku, D. J., Gichaba, M. A., \& Koech, M. (2017). Challenges Facing in the Implementation of Early Childhood Development Education in Kericho Country, Kenya. International Journal of Research in Education and Psychology (IJREP), 3 (1), 1-16.

Mutindi, K. Z., Chepngeno, K. R. \& Jeruto, B. (2016). Teacher Factors Affecting the Implementation of Early Childhood Development Education in Kericho Municipality, Kericho County. Journal of Education and Practice, 7(15),155-161.

Onyango, W. P. (2014). Effects of Teaching and Learning Resources on preschool learners Transition to class one; A case study of Rachuonyo South Sub- County. Journal of education and practice, 5(34).

Orodho, J. A. (2009). Elements of education and social science research methods. Nairobi/Masen $o, 2(6), 26-133$.

Rao, P. (2002). Greening the supply chain: a new initiative in South East Asia. International Journal of Operations \& Production Management.

Tonui, B. C. E. (2015). Integration of creative art and drama in enhancing the teaching and learning in ECDE and primary schools in Kenya. International Journal of Sciences: Basic and Applied Research, 23 (1), 34-41.

Whitebread, D. (2010). Play, metacognition and self-regulation. Play and learning in the early years, 161-176.

Willis, J. E., \& Hymon-Parker, S. (2010). Expanding multicultural activities across the curriculum for preschool http://www.kon.org/ur c/v5/willis.html. 